\title{
ANALISA KUALITAS BRIKET ARANG (STUDI KASUS TANAMAN BAMBU DI HUTAN PENDIDIKAN DESA HONITETU KABUPATEN SERAM BAGIAN BARAT)
}

\author{
QUALITY ANALYSIS OF CHARCOAL BRIQUETTES \\ (CASE STUDY OF BAMBOO PLANTS IN HONITETU VILLAGE EDUCATION FOREST WEST \\ SERAM REGENCY)
}

\author{
Oleh \\ Jimmy Titarsole ${ }^{1)}$, Rohny S Maail ${ }^{2)}$ \\ ${ }^{1,2)}$ Jurusan Kehutanan Fakultas Pertanian Universitas Pattimura \\ Email: jimmytitarsole@ gmail.com

\begin{tabular}{|l|l} 
Diterima: 8 Februari2021 & Disetujui: 29 Maret 2021
\end{tabular}

\begin{abstract}
Abstrak
Penelitian ini bertujuan menganalisis hubungan antara bambu (jenis bambu jawa (Schizostachyum brachycladum), bambu petung (Dendrocalamus asper) dan bambu suanggi (Schizostachyum arundinaceae)] dengan tekanan (perlakuan 3 ton, 2.5 ton dan 2 ton) terhadap kualitas briket arang. Prosedur penelitian diawali dengan persiapan bahan baku, pengeringan, pengarangan, penghalusan, percampuran perekat, percetakan dan pengempaan, pengeringan briket dan penentuan mutu briket. Penelitian ini menggunakan Rancangan Acak Lengkap (RAL) yang di susun secara faktorial dengan 3 kali ulangan dimana dengan faktor yang diteliti ada 2 faktor yaitu: faktor A (jenis bambu) dan faktor B (tekanan/kempa). Hasil penelitian menunjukan bahwa analisis keragaman jenis bambu (A) berpengaruh terhadap kadar air kering udara dan nilai kalor, faktor tekanan (B) dan interaksi (AB) berpengaruh terhadap kasar air kering udara sedangkan parameter lainnya tidak berpengaruh. Nilai kadar air kering udara berkisar antara 6,55-6,62\%, kadar air kering oven berkisar antara 3,426-3,446\%, kadar abu berkisar antara 4,154-4,240\%, kadar zat mudah menguap berkisar antara 7,64-7,99\%, kadar karbon terikat berkisar antara 60,295-60,456\% dan nilai kalor berkisar antara 4336,28$4833.24 \mathrm{cal} / \mathrm{g}$. Hasil Penelitian Memenuhi Standar SNI 01-6235-2000.
\end{abstract}

Kata Kunci: bambu (Bambusa sp), tekanan, briket arang, nilai kalor

\begin{abstract}
This study aims to analyze the relationship between bamboo (Javanese bamboo species (Schizostachyum brachycladum), petung bamboo (Dendrocalamus asper) and suanggi bamboo (Schizostachyum arundinaceae)] with pressure ( 3 tons, 2.5 tons and 2 tons treatment) on the quality of charcoal briquettes. The research procedure begins with the preparation of raw materials, drying, curing, grinding, adhesion, printing and pressing, drying briquettes and determining the quality of the briquettes. This study used a Completely Randomized Design (CRD) arranged in factorial with 3 replications where the factors studied were 2 factors: factor A (bamboo type) and factor B (pressure). The results showed that the analysis of bamboo species diversity (A) affected the air-dry water content and the heating value, pressure factor $(B)$ and interaction $(A B)$ affected the roughness of air-dried water while the other parameters did not affect. The value of dry air content ranges between 6.55-6.62\%, Dry oven water levels range between 3.426$3.446 \%$, ash content ranges between $4.154-4.240 \%$, volatile substance levels range between 7.64-7.99\%, bonded carbon content ranges between 60.295-60.456\% and and heating value ranges from 4336.28-4833.24 cal/g. Research Results Meet SNI Standards SNI 01-6235-2000.
\end{abstract}

Keywords: bamboo (Bambusa sp), pressure, charcoal briquettes and calorific value 


\section{PENDAHULUAN}

Produk Hasil Hutan Bukan Kayu dalam pemanfaatannya memiliki keunggulan dibandingkan dengan hasil hutan kayu sehingga hasil hutan bukan kayu memiliki prospek yang besar dalam pengembangannya. Pemanfaatan hasil hutan bukan kayu tidak menimbulkan kerusakan yang besar, mudah dipanen dan diikuti dangan waktu panen yang tidak terlalu lama, teknik pemanenan dilakukan secara sederhana sehingga kerusakan yang terjadi tidak begitu besar dibanding dengan pemanenan kayu, Bambu termasuk salah satu produk hasil hutan bukan kayu yang memiliki luasan areal produksi yang cukup luas karena siklus pertumbuhannya sangat cepat. Bambu tergolong keluarga gramineae (rumput-rumputan), berumpun dan terdiri dari sejumlah batang (buluh) yang tumbuh secara bertahap, dari mulai rebang, batang mudah dan sudah dewasa pada umur 4-5 tahun. Batang bambu berbentuk selindris, berbuku-buku beruas-ruas berungga kadang kadang masih, berdinding keras, pada setiap buku terdapat mata tunas atau cabang. Akar bambu terdiri atas rimpang (rhizon) berbuku dan beruas, pada buku akan ditumbuhi oleh serabut dan tunas yang dapat tumbuh menjadi batang.

Bambu telah lama dikenal masyarakat Indonesia dan dimanfaatkan oleh berbagai lapisan masyarakat, sehingga produk bambu selalu berhubungan erat dengan perkembangan budaya bangsa Indonesia. Bahwa $80 \%$ bambu di Indonesia di gunakan untuk konstruksi (termasuk mebel), $10 \%$ untuk pembungkus, 5\% untuk bahan baku kerajinan, (industri kecil) serta 5\% untuk sarana pertanian dan lain-lain. Selain itu bambu dapat dimanfaatkan juga untuk produk arang dan briket arang.

Beriket arang atau yang sering disebut dengan superkarbon adalah bahan bakar karbon dalam bentuk briket yang di produksi dari limbah bahan organik maupun turunannya yang masih mengandung sejumlah energi. Kualitas briket yang dihasilkan ditentukan dengan nilai kalor pada briket tersebut. Nilai kalor ini dipengaruhi oleh tekanan, suhu dan jenis bahan baku. Tekanan atau pengampaan diperlukan dalam pembuatan arang briket untuk membentuk beriket sehingga dapat dipergunakan sebagai bahan bakar sebagaimana arang pada umumnya. Soeparno (1993) mengemukakan bahwa besarnya pengempaan dan temperatur berpengaruh secara signifikan terhadap rendemen arang briket yang di hasilkan. Selain pengempaan dan temperatur jenis bahan baku juga dapat mempengaruhi briket arang.

Pada umumnya masyarakat di Maluku dapat memanfaatkan jenis bambu untuk beragam kebutuhan dan kegiatan masyarakat. Hutan Pendidikan Fakultas Pertanian di Desa Honitetu memiliki potensi flora dan fauna yang melimpah. Salah satu hasil hutan bukan kayu adalah bambu. Jenis bambu di desa Honitetu terdiri dari tiga jenis bambu yaitu bambu jawa, (Schizostachyum brachycladum) dimanfaatkan untuk pencorang rumah, bambu petung (Dendrocalamus asper) dimanfaatkan sebagai bahan kontruksi rumah (tiang), rebungnya sangat disukai penduduk, dan bambu suanggi (Schizostachyum arundinaceae) dimanfaatkan sebagai tongkat (steling) dalam membangun rumah. Besarnya manfaat bambu untuk masyarakat maka diperlukan adanya 
rekayasa perlakuan sehingga dapat meningkatkan nilai dari limbah bambu menjadi briket arang yang berkualitas.

Penelitian ini bertujuan untuk: 1) Mengetahui pemanfaatan jenis bambu menjadi briket arang dengan menggunakan perekat tepung

\section{METODE PENELITIAN}

Penelitian ini dilakukan di Desa Honitetu, Kecamatan Inamosol, Kabupaten Seram Bagian Barat. Kegiatan pelaksanaan penelitian ini meliputi pengambilan bahan baku selama \pm 1 minggu di lapangan dilanjutkan pengujian di laboratorium Teknologi Hasil Hutan Fakultas Pertanian Universitas Pattimura Ambon dan Laboratorium PAU UGM untuk pengujian nilai kalor. Penelitian dilaksanakan pada bulan Juli 2019. Bahan baku yang digunakan dalam penelitian ini adalah sebagai berikut: bambu jawa (Schizostachyum brachycladum), bambu petung (Dendrocalamus asper), bambu suanggi (Schizostachyum arundinaceae), tepung tapioka, sebagai bahan perekat, dan air sebagai bahan pembantu dalam proses pembuatan perekat. enelitian ini

\section{Persiapan Bahan baku}

Persiapan bahan dilakukan sebelum proses pembuatan briket. Bahan baku terdiri dari bambu jawa, bambu petung, dan bambu suanggi.

\section{Pengeringan bahan baku}

Tiga jenis bambu yang masih segar kemudian dikeringkan dengan cara dijemur dibawah sinar matahari sampai kering udara.

\section{Pengarangan}

Tiga jenis bambu yang telah kering kemudian diarangkan dengan alat yang di sediakan. Cara kerja pengarangan sebagai berikut:

\section{Penghalusan dan pengayakan}

Seluruh arang yang dihasilkan biasanya masih berbentuk aslinya. Maka hasil dari pengarangan ini perlu ditumbuk atau dihaluskan, dimana proses penghalusan dilakukan dengan cara manual yaitu dengan menggunakan palu. Kemudian arang tapioka sebagai bahan bakar alternatif; dan 2) Menganalisis hubungan antara jenis bambu (bambu jawa, bambu suanggi, bambu petung) dengan berbagai jenis tekanan terhadap kualitas briket arang.

menggunakan pendekatan kuantitatif dengan mengumpulkan data primer dan data sekunder. Data primer berasal dari pengujian briket dengan parameter meliputi kadar air, kadar abu, kadar zat mudah menguap, kadar karbon terikat dan nilai kalor sedangkan data sekunder didapat dari hasil survei, jurnal dan buku yang berhubungan dengan penelitian.

Tahapan penelitian merupakan kerangka acuan yang akan digunakan dalam proses pelaksanaan penelitian. Pelaksanaan penelitian dilakukan dengan pengujian briket dengan parameter meliputi kadar air, kadar abu, kadar zat mudah menguap, kadar karbon terikat, dan nilai kalor. Penelitian ini menggunakan tiga jenis bambu sebagai perbandingan.

a. Tiga jenis bambu yang telah di jemur dibawah sinar matahari dimasukan ke dalam alat yang disiapkan sesuai jenis bambunya,

b. Proses pembakaran tiga jenis bambu menghasilkan asap yang terbuang melalui cerobong asap pada alat tersebut.

c. Asap yang keluar dari corobong sudah berkurang berarti proses pengarangan sudah selesai

d. Kemudian arang diambil untuk di haluskan dan di ayak sebesar 35 mesh.

yang sudah halus diayak dengan menggunakan saringan yang mempunyai skala 35 mesh.

Proses pengayakan dilakukan agar ukuran butiran arang yang didapatkan memiliki ukuran yang sama. 


\section{Persiapan Perekat}

Bahan perekat yang digunakan adalah tapioka. Proses pembuatan perekat sebagai berikut: a.Siapkan bahan perekat.

b.Tepung tapioka ditimbang lalu dicampur dengan air (Perbandingan air dan tepung tapioka adalah $1: 10)$

c.Panaskan dan aduk agar mengental dan terasa lengket di tangan.

\section{Pencampuran Perekat dan Bahan Baku}

Tiga jenis bambu yang telah dihaluskan dan diayak dengan saringan ukuran 35 mesh kemudian dilakukan pencampuran dengan perekat tepung tapioka $20 \mathrm{~g}$ dengan perbandingan serbuk arang $50 \mathrm{~g}$ dan air $30 \mathrm{ml}$. Pencampuran perekat dan arang dilakukan secara manual.

\section{Penentuan Mutu Briket}

\section{Penentuan Kadar Air (SNI 06-37301996)}

Kadar air briket dapat ditentukan dengan cara menimbang cawan porselin kosong kemudian sampel briket dimasukkan ke cawan sebanyak $5 \mathrm{~g}$. Sampel diratakan dan dimasukkan ke dalam oven yang telah diatur suhunya sebesar $105^{\circ} \mathrm{C}$ selama 3 jam. Cawan dikeluarkan dari oven dan didinginkan dalam desikator kemudian ditimbang bobotnya. Penentuan kadar air dilakukan sebanyak tiga kali pengulangan. Kadar air dapat ditentukan dengan menggunakan persamaan:

$$
\% \text { Kadar Air Briket Arang }=\frac{a-b}{a} \times 100 \%
$$

Dimana: $\mathrm{a}=$ Massa awal briket $(\mathrm{g}), \mathrm{b}=$ Massa briket setelah pemanasan $(\mathrm{g})$

\section{Penentuan Kadar Abu (SNI 063730-1996)} Penentuan kadar abu dilakukan dengan cara Penentuan Kadar Zat Mudah Menguap pada Suhu $950^{\circ} \mathrm{C}$ (SNI 06-37301996)

Cara penentuan kadar zat yang hilang pada suhu $950^{\circ} \mathrm{c}$ briket yaitu cawan kosong beserta tutupnya terlebih dahulu dipijarkan di dalam tanur selama 30 menit dan didinginkan di dalam desikator. Kemudian ditimbang dengan teliti sebanyak $1 \mathrm{~g}$ sampel ke dalam cawan kosong tersebut. Cawan selanjutnya ditutup dan dimasukkan ke dalam tanur dengan suhu $950^{\circ} \mathrm{C}$ selama 7 menit. Penentuan kadar zat yang hilang pada suhu $950^{\circ} \mathrm{C}$ dilakukan sebanyak tiga kali pengulangan (triplo). Kadar zat yang hilang pada suhu $950^{\circ} \mathrm{C}$ dapat dihitung dengan menggunakan rumus:

$\% \mathrm{~V} \mathrm{~m}=\frac{a-d}{a} \times 100 \%$

\section{Pencetakan dan Pengempaan}

Pencetakan arang bertujuan untuk memperoleh bentuk yang seragam dan memudahkan dalam pengemasan serta penggunaannya. Komposisi bahan baku yang telah dibuat selanjutnya dimasukkan dalam cetakan berukuran diameter $2 \mathrm{~cm}$ dan tinggi 5 $\mathrm{cm}$. Pengempaan dilakukan dengan tekanan kempa 2 ton, 2.5 ton dan 3 ton.

\section{Pengeringan Briket}

Briket yang telah di cetak masih memiliki kadar air yang tinggi sehingga bersifat basah dan lunak. Briket yang dihasilkan dikeringkan dalam oven dengan suhu $100^{\circ} \mathrm{C}$ selama kurang lebih 4 jam.

mengeringkan cawan porselin dalam tanur bersuhu $600^{\circ} \mathrm{C}$ selama 30 menit. Selanjutnya cawan didinginkan di dalam eksikator selama 30 menit dan ditimbang bobot kosongnya. Kemudian ke dalam cawan kosong tersebut dimasukkan sampel sebanyak $1 \mathrm{~g}$. Cawan yang telah berisi sampel selanjutnya dimasukkan ke dalam tanur dengan suhu $850^{\circ} \mathrm{C}$ selama 4 jam sampai sampel menjadi abu. Selanjutnya cawan diangkat dari dalam tanur dan didinginkan di dalam eksikator, lalu ditimbang. Penentuan kadar abu dilakukan sebanyak tiga kali pengulangan. Kadar abu dapat dihitung dengan menggunakan rumus:

$$
\begin{aligned}
& \text { Kadar abu }(\%)=\frac{a}{b} \times 100 \% \\
& \text { Dimana: a = bobot abu (gram), } \\
& \text { b = bobot sampel (gram) }
\end{aligned}
$$

Dimana: $\mathrm{a}=$ bobot sampel awal (gram), $\mathrm{b}=$ bobot sampel setelah pemanasan (gram).

\section{Penetapan Kadar Karbon Terikat (Fixed Carbon) SNI 01-1682-1996}

Karbon terikat (fixed carbon) adalah fraksi karbon (C) yang terikat di dalam arang selain fraksi air, zat menguap dan abu. Keberadaan karbon terikat di dalam briket arang dipengaruhi oleh kadar air, kadar abu dan kadar zat menguap. Kadarnya akan bernilai tinggi apabila kadar air, kadar abu dan kadar zat menguap pada briket rendah. Karbon terikat berpengaruh terhadap nilai kalor pembakaran briket arang. Nilai kalor briket arang akan tinggi. Dapat dihitung dengan menggunakan rumus: 


$$
\% \mathrm{C}=100 \%(\mathrm{Ka}+\mathrm{Vm}+\mathrm{Abu}) \%
$$

\section{Penetapan Nilai Kalor (heating value) SNI 01- 1682-1996}

Penetapan nilai kalor bakar briket merupakan salah satu parameter untuk menentukan kualitas briket dalam penggunaannya, layak atau tidak digunakan sebagai bahan bakar. Nilai kalor merupakan parameter utama pengukuran kualitas bahan bakar, bertujuan untuk mengetahui nilai panas pembakaran yang dihasilkan briket. Semakin tinggi nilai kalor, semakin baik kualitas briket yang dihasilkan dan harga jualnya pun akan tinggi (Wibowo, 2012). Semakin tinggi kandungan karbon terikat pada briket arang maka semakin tinggi pula nilai kalor briket arang yang dihasilkan. Panas yang diserap air dalam bomb calorimeter dihitung dengan menggunakan rumus:

$$
\mathrm{Q}=\mathrm{m} \cdot \mathrm{Cp} . \Delta \mathrm{T}
$$

Dimana: $\mathrm{Q}=$ Panas yang diserap $(\mathrm{kJ}) ; \mathrm{m}=$ Massa air di dalam bomb calorimeter (gram); $\mathrm{Cp}=$

\section{Rancangan Penelitian}

Penelitian ini menggunakan Rancangan Acak Lengkap Gaspersz (1989) dan Faulina et al. (2011) yang di susun secara faktorial dengan 3 kali ulangan

\section{HASIL DAN PEMBAHASAN}

\section{Penetapan Kadar Air Kering Udara (KAKU)}

Kadar air dalam pembuatan briket arang sangat berpengaruh pada kualitas briket arang. Semakin tinggi kadar air akan menyebabkan kualitas briket arang menurun, terutama berpengaruh pada nilai kalor brket arang dan briket arang sulit dinyalakan
Dimana $: \mathrm{Ka}=\%$ kadar air; $\mathrm{Vm}=\%$ penetapan kadar zat mudah menguap; $\mathrm{Abu}=$ penetapan kadar abu

Specific heat $4,186 \mathrm{~kJ} / \mathrm{kg}^{\circ} \mathrm{C} ; \Delta \mathrm{T}=$ Perbedaan temperatur $\left({ }^{\circ} \mathrm{C}\right)$

LHV dan HHV dihitung dengan

1) Menggunakan rumus berikut:

$$
\mathrm{LHV}=\frac{\mathrm{mx} \mathrm{Cpx} \Delta \mathrm{T})}{m_{\text {briket }}}
$$

2) Untuk menghitung HHV digunakan rumus :

$$
\begin{aligned}
\mathrm{HHV} & =(\mathrm{T} 2-\mathrm{T} 1-\mathrm{Tkp}) \times \mathrm{CV}(\mathrm{kJ} / \mathrm{kg}) \\
\mathrm{LHV} & =\mathrm{HHV}-3240 \mathrm{~kJ} / \mathrm{kg} \\
\mathrm{HHV} & =\mathrm{LHV}+3240 \mathrm{~kJ} / \mathrm{kg}
\end{aligned}
$$

Dimana: $\mathrm{T} 1=$ Temperatur air pendingin bomb calorimeter sebelum pembakaran $\left({ }^{\circ} \mathrm{C}\right) ; \mathrm{T} 2=$ Temperatur air pendingin bomb calorimeter sesudah pembakaran $\left({ }^{\circ} \mathrm{C}\right)$; Tkp $=$ Kenaikan temperature disebabkan kawat pembakaran, $0.05^{\circ} \mathrm{C} ; \mathrm{HHV}=$ Higthest Heating Value $(\mathrm{kJ} / \mathrm{kg})$; $\mathrm{LHV}=$ Lowest Heating Value $(\mathrm{kJ} / \mathrm{kg})$.

2 faktor yang diteliti yaitu: faktor A meliputi jenis bambu diantaranya bambu jawa (a1), bambu patung (a2) dan bambu suanggi (a3) dan faktor B meliputi tekanan/kempa diantaranya tekanan 3 ton (b1), tekanan 2,5 ton (b2) dan tekanan 2 ton (b3).

(Putra et al., 2014). Rata-rata kadar air kering udara briket arang bambu (Bambusa sp) terbesar $6,62 \%$ yang diperoleh pada perlakuan bambu suanggi dengan tekanan 3 ton (a3b1) dan terendah sebesar $6,55 \%$. pada perlakuan bambu patong dengan tekanan 3 ton (a2b1). 


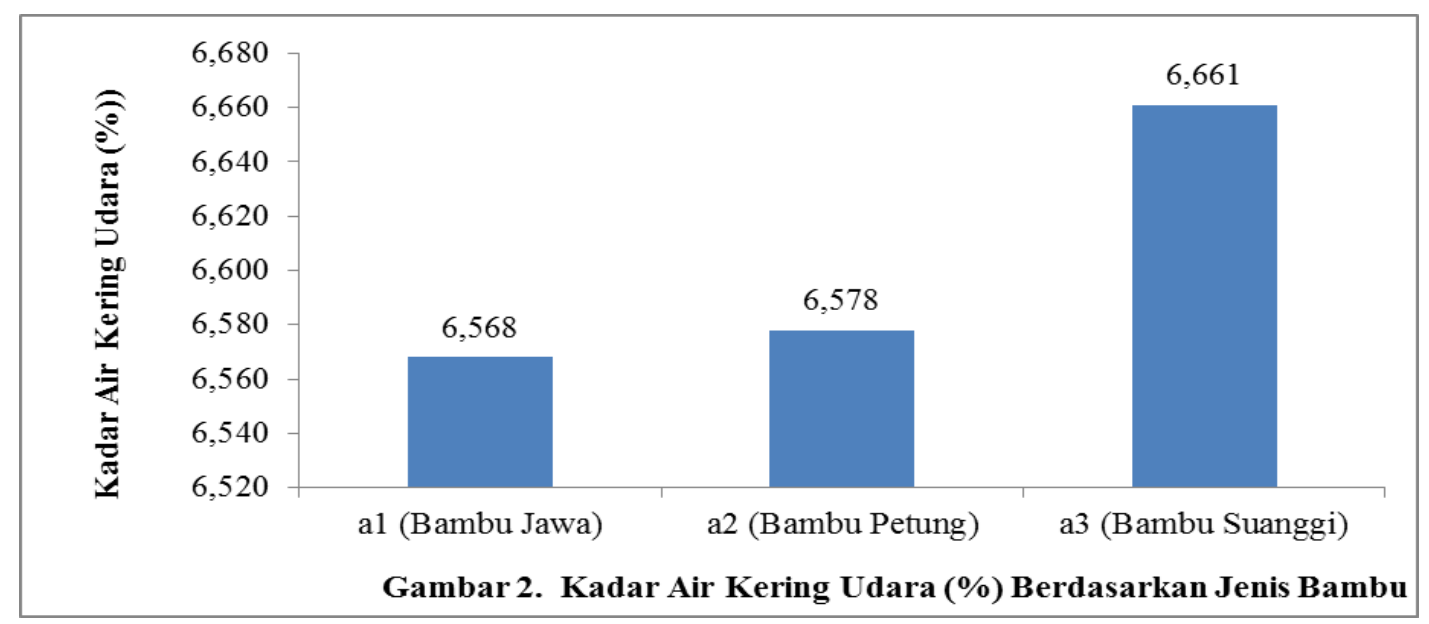

Berdasarkan hasil penelitian ini dapat tekanan memperlihatkan tekanan 3 ton (b1) dilihat nilai hasil perlakuan jenis bambu pada briket memiliki nilai yang rendah sebesar $6,570 \%$ diikuti arang pada bambu jawa (a1) meberikan nilai yang dengan tekanan 2,5 ton (b2) sebesar 6,586\% dan cukup rendah, dibandingkan dengan bambu petung (a2) dan bambu suanggi (a3) kadar airnya sangat tinggi (Gambar 2). Tingginya kadar air disebabkan karena memiliki ukuran partikel yang lebih besar dan jumlah pori-pori yang lebih banyak (Putro et al., 2014). Kadar air kering udara berdasarkan besarnya tinggi pada perlakuan tekanan 2 ton (a3) yaitu sebesar 6,594\%. dapat dilihat pada Gambar 5. Hal ini diduga dipengaruhi oleh kadar abu dimana makin tinggi kadar abu semakin rendah kadar air. Abu disusun oleh silika yang mempunyai kemampuan menyerap air yang kecil (Anggoro et al., 2017).

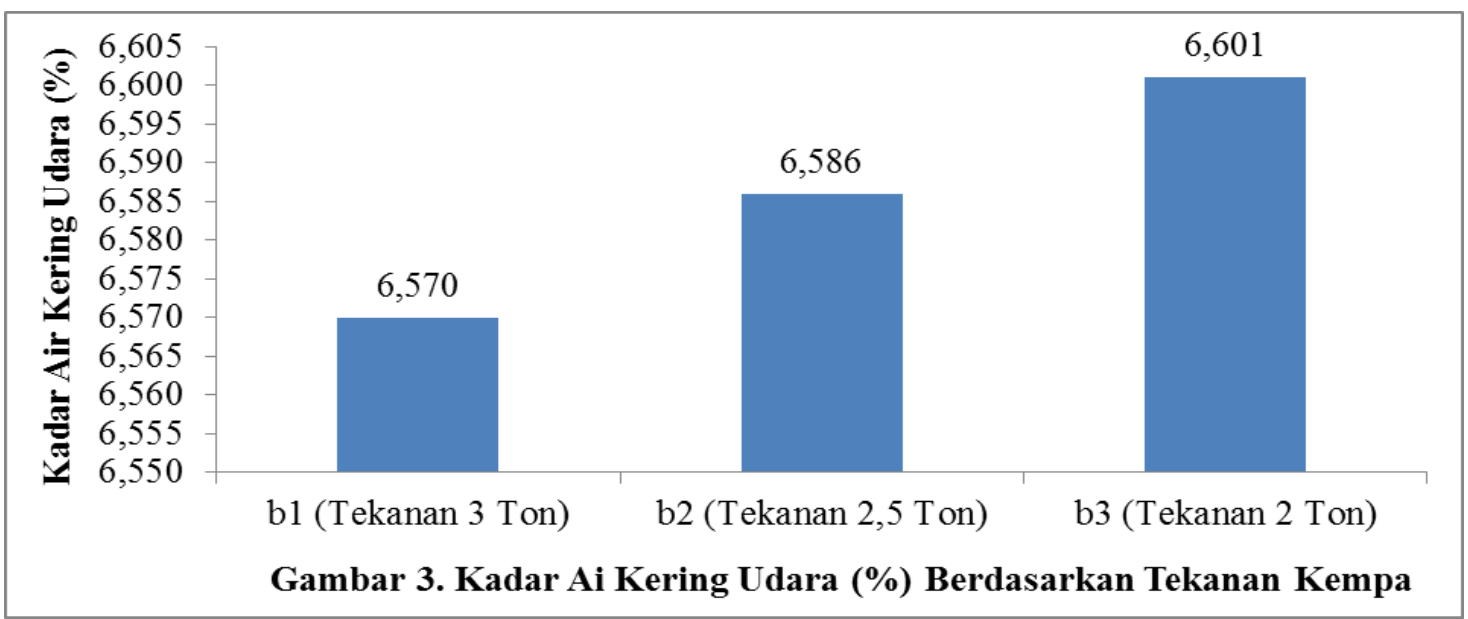

Briket arang dengan tekanan 2 ton

(b3) memberikan nilai yang cukup tinggi di Kadar air rendah karena kerapatan sangat tinggi akibatkan karena kerapatan pada briket arang sangat rendah sehingga mengakibatkan kadar air pada briket arang sangat tinggi dibandingkan dengan tekanan 2,5 ton (b2) dan tekanan 3 ton (b1). dipengaruhi oleh tekanan yang diberikan sangat besar, hal ini sesuai dengan pernyataan Esmar (2017). Berdasarkan hasil analisis sidik ragam, terlihat bahwa jenis bambu dan tekanan berpengaruh sangat nyata terhadap perlakuan kadar 
air kering udara sedangkan pada hasil uji beda nyata jujur, terlihat bahwa hasil rata-rata pengaruh jenis bambu terhadap kadar air dalam bentuk persen dimana perlakuan bambu jawa (a1) mempunyai nilai kadar air yang rendah bila di bandingkan dengan perlakuan bambu petung (a2) dan bambu suanggi (a3) yang memiliki nilai kadar air yang tinggi. Hal ini sesuai dengan Sarjono (2013) yang menyatakan bahwa arang memiliki kemampuan menyerap air yang besar yang dipengaruhi oleh luas permukaan dan pori-pori arang.

Untuk mengetahui pengaruh perlakuan maka dilakukan analisis ragam pada Tabel 2. Jenis bambu (A), tekanan (B) dan interaksinya (AB), berpengaruh sangat nyata terhadap kadar air kering udara briket arang bambu. Berdasarkan hasil analisis sidik ragam pada Tabel 2, terlihat bahwa jenis bambu dan tekanan berpengaruh sangat nyata terhadap perlakuan kadar air kering udara,

\section{Penetapan Kadar Air Kering Oven}

Arang sangat mudah untuk menyerap air dan melepaskan air karena memiliki sifat hidroskopis yang tinggi. Menurut Hendra (2007) bahwa permukaan yang seragam akan memudahkan arang untuk menempel dan berikatan satu sama lainnya. Ditambahkan dengan tekanan pengempaan yang membantu proses pengikatan dan pengisian ruang- sedangkan pada hasil uji beda nyata jujur, terlihat bahwa hasil rata-rata pengaruh jenis bambu terhadap kadar air kering udara dalam bentuk persen dimana perlakuan bambu jawa (a1) mempunyai nilai kadar air kering udara yang rendah bila d bandingkan dengan perlakuan bambu petung (a2) dan bambu suanggi (a3) memiliki nilai kadar air kering udara yang tinggi.

Makin besar tekanan yang diberikan maka semakin kecil atau rendah nilai kadar air yang dihasilkan. Hal ini menunjukan bahwa kadar air kering udara juga dipengaruhi oleh tekanan, ini disebabkan karena tekanan yang diberikan besar sehingga mengakibatkan kadar air mudah keluar (Esmar, 2017). Nilai kadar air standarisasi Inggris sebesar 3,6\%, USA sebesar 6,2\% dan nilai kadar air standarisasi Jepang sebesar 6-8 \% sedangkan briket arang bambu (Bambusa sp) memiliki kadar air terendah sebesar $6,55 \%$ dan tertinggi sebesar $6,62 \%$.

ruang koson sedangkan ukuran partikel yang tidak seragam akan menyebabkan ikatan antar partikel serbuk arang yang tidak sempurna. Rata-rata kadar air kering oven briket arang bambu (Bambusa $s p$ ) terbesar sebesar 3,446\% yang diperoleh pada perlakuan bambu petung dengan tekanan 2 ton (a2b3) dan terendah sebesar 3,426\%. pada perlakuan bambu jawa dengan tekanan 2,5 ton (a1b2). 


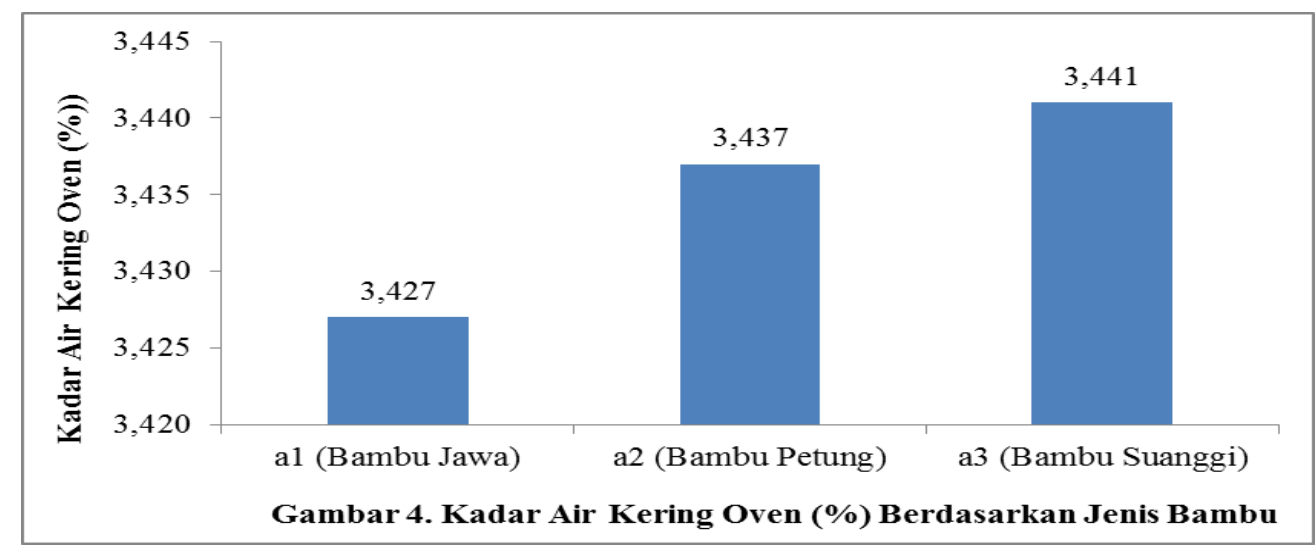

Briket arang pada bambu jawa (a1) 2,5 ton (b2) sebesar 3,435 \% dan tertinggi pada memberikan nilai yang cukup rendah, di bandingkan perlakuan tekanan 2 ton (a3) yaitu sebesar 3,437\% dengan bambu petung (a2) dan bambu suanggi (a3) kadar air sangat tinggi. Kadar air kering oven berdasarkan besarnya tekanan/kempa memperlihatkan tekanan 3 ton (b1) memiliki nilai dapat dilihat pada gambar 5. Kadar air briket arang yang rendah berpeluang menghasilkan nilai kalor yang tinggi diikuti oleh merangsangnya pertumbuhan anakan (Gusmailina, 2010). yang rendah sebesar 3,433\% diikuti dengan tekanan

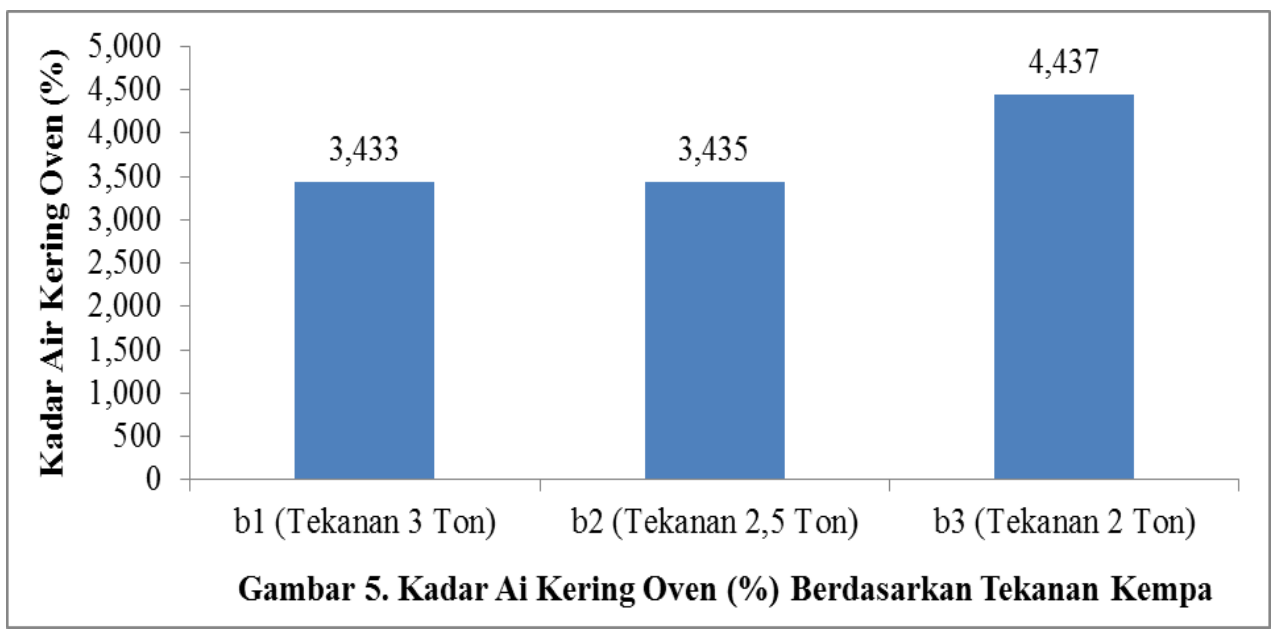

Briket arang dengan tekanan 2 ton (b3) 2016). Hal ini sesuai dengan hasil penelitian Badan memberikan nilai yang cukup tinggi di akibatkan Penelitian dan Pengembangan Kehutanan (2014) karena kerapatan pada briket arang sangat rendah sehingga mengakibatkan kadar air kering oven pada briket arang sangat tinggi dibandingkan dengan bahwa briket arang dengan ukuran serbuk yang lolos 20 mesh memiliki kadar air paling tinggi dengan arang serbuk yang lolos saringan 40 mesh tekanan 2,5 ton (b2) dan tekanan 3 ton (b1) kadar air sangat rendah karena kerapatan sangat tinggi dipengaruhi oleh tekanan yang diberikan sangat dan 80 mesh.

Berdasarkan hasil analisis ragam terlihat besar, sesuai dengan pernyataan (Hastiawan et al., bahwa jenis bambu dan tekanan berpengaruh tidak nyata terhadap perlakuan kadar air kering oven. 
Jenis bambu (A), tekanan (B) dan interaksinya (AB) berpengaruh tidak nyata terhadap pengaru kadar air

\section{Penetapan Kadar Abu}

Kadar abu terjadi dari sisa pembakaan yang sudah tidak memiliki nilai kalor atau tidak memiliki unsur karbon lagi. Salah satu unsur penyusun abu adalah silika. Pengaruh kadar abu terhadap kualitas briket arang kurang baik terhadap nilai kalor yang dihasilkan. Kandungan kadar abu yang tinggi dapat kering oven briket arang bambu.

menurunkan nilai kalor briket arang sehingga akan menurunkan kualitas briket arang (Rahadian et al., 2013). Rata-rata kadar abu briket arang bambu (Bambusa sp) terbesar sebesar 4,240 \% yang diperoleh pada perlakuan bambu jawa dengan tekanan 2,5 ton (a1b2) dan terendah sebesar 4,154 $\%$. pada perlakuan bambu suanggi dengan tekanan 2,5 ton $(\mathrm{a} 3 \mathrm{~b} 2)$.

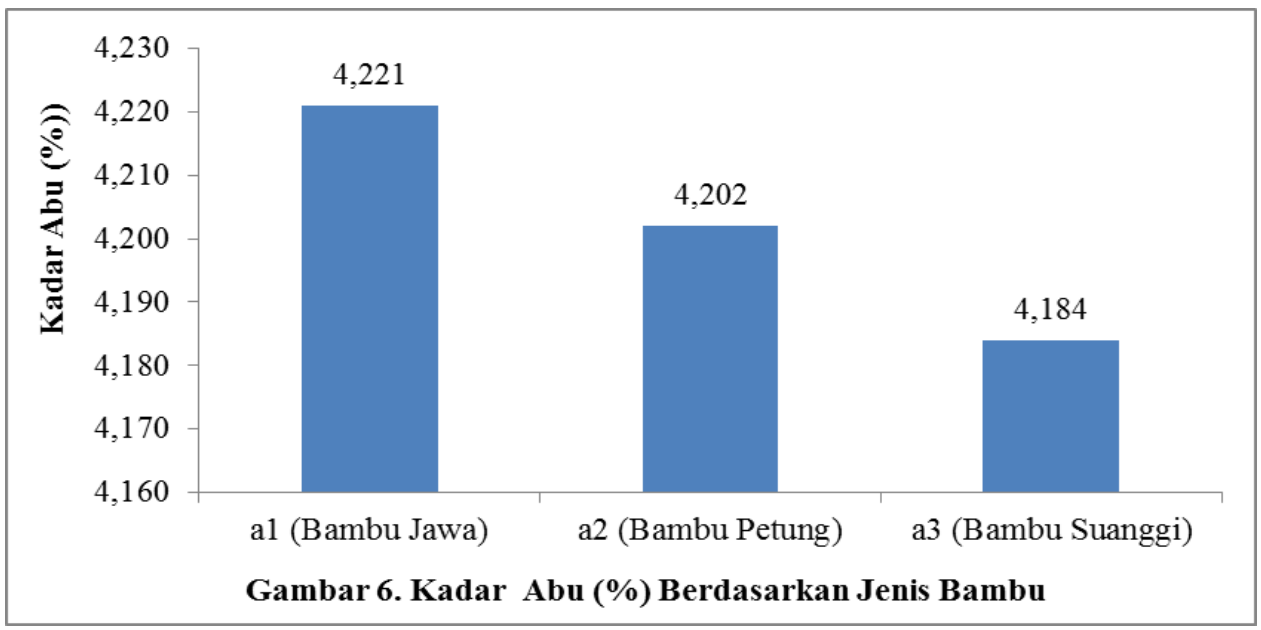

Briket arang bambu jawa (a1) memberikan ton (b1) memiliki nilai yang rendah sebesar 4.195 nilai yang cukup tinggi, di bandingkan dengan $\%$ diikuti dengan tekanan 2,5 ton (b2) sebesar 4,200 bambu petung (a2) dan bambu suanggi (a3) kadar $\%$ dan tertinggi pada perlakuan tekanan 2 ton (a3) abu yang sangat rendah. Kadar abu berdasarkan yaitu sebesar 4,207 \%. dapat dilihat pada Gambar 7 . besarnya tekanan/kempa memperlihatkan tekanan 3 


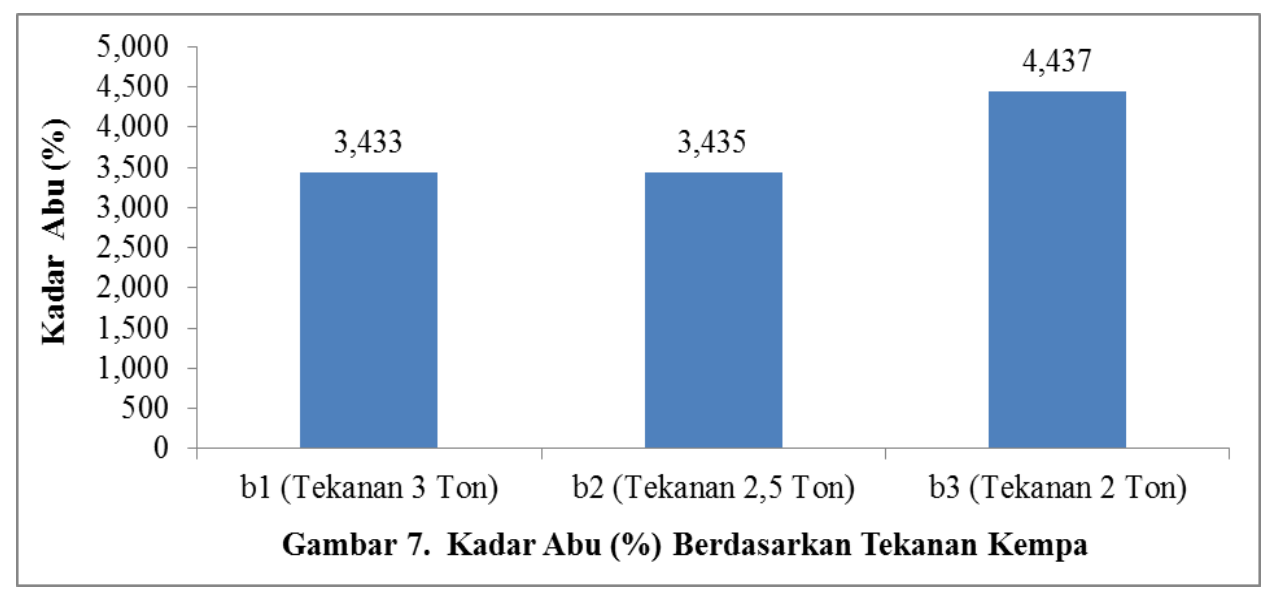

Briket arang pada tekanan 2 ton (b3) menghasilkan nilai kalor yang tinggi (Sudradjat dan memberikan nilai yang cukup tinggi di akibatkan karena kerapatan pada briket arang sangat rendah sehingga mengakibatkan kadar abu pada briket arang sangat tinggi dibandingkan dengan tekanan 2,5 ton (b2) dan tekanan 3 ton (b1). Kadar abu rendah karena kerapatan yang terbentuk tinggi yang dipengaruhi oleh tekanan yang diberikan. Komponen kandungan abu juga dipengaruhi oleh komponen silika yang ada di abu. Peningkatan banyaknya kandungan silika selalu diikiti oleh peningkatan kandungan abu (Hendra dan Darmawan, 2000).

Berdasarkan hasil analisis ragam terlihat bahwa jenis bambu dan tekanan berpengaruh tidak nyata terhadap perlakuan kadar abu. Jenis bambu $(\mathrm{A})$, tekanan $(\mathrm{B})$ dan interaksinya $(\mathrm{AB})$ berpengaruh tidak nyata terhadap pengaruh kadar abu briket arang bambu. Kadar abu yang rendah berpeluang Pari, 2011)

\section{Penetapan Kadar Zat Mudah Menguap}

Kadar zat mudah menguap sebagai zat (volatile matter) yang dapat menguap sebagai hasil dekomposisi senyawa-senyawa yang masih terdapat di arang selain air. Kandungan kadar zat mudah menguap yang tinggi didalam briket arang akan menyebabkan asap yang lebih banyak pada saat briket dinyalakan, Kandungan asap yang tinggi disebabkan oleh adanya reaksi antara karbon monoksida (CO) dengan unsur alkohol (Hendra dan Pari, 2000). Rata-rata kadar zat mudah menguap briket arang bambu (Bambusa sp) terbesar sebesar $7,99 \%$ yang diperoleh pada perlakuan bambu petung dengan tekanan 2,5 ton (a3b2) dan terendah sebesar 7,64\%. pada perlakuan bambu jawa dengan tekanan 2 ton (a1b3).

DOI:1030598/jhppk.2021.5.1.40 


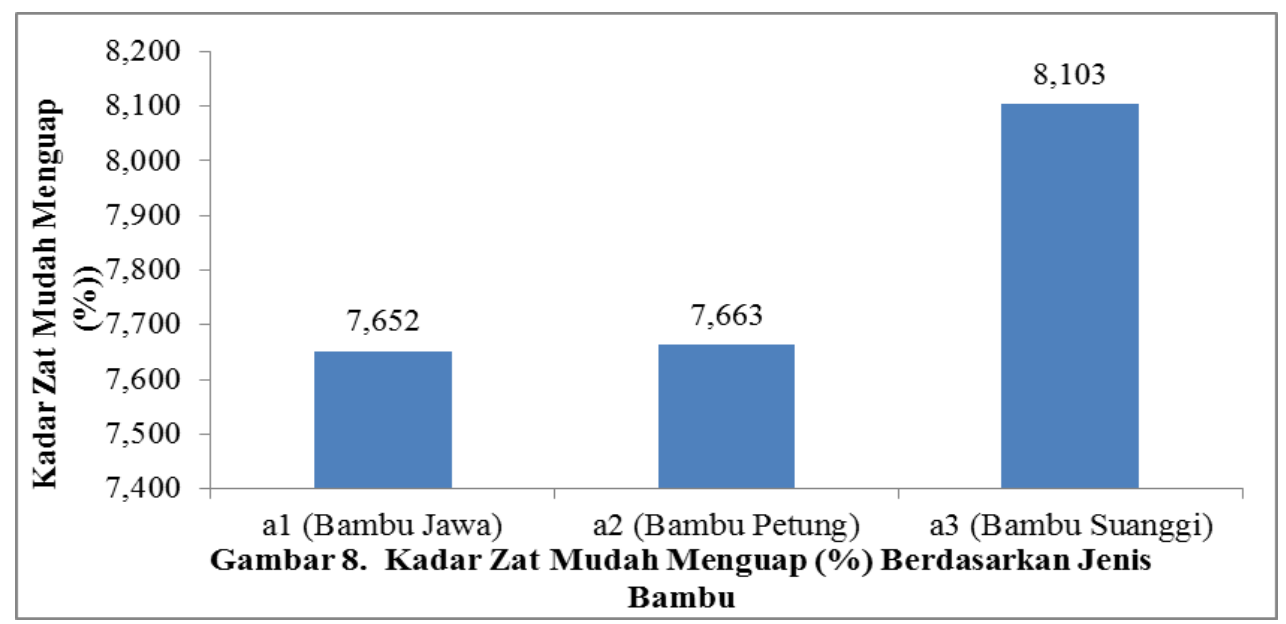

Briket arang bambu jawa (a1) memberikan dapat dilihat pada Gambar 9. Tinggi rendahnya nilai yang cukup rendah, dibandingkan dengan kadar zat mudah menguap pada briket arang diduga bambu suanggi (a3) dan bambu petung (a2) kadar disebabkan oleh kesempurnaan proses karbonisasi zat mudah menguap sangat tinggi. Kadar zat mudah dan juga dipengaruhi oleh waktu dan suhu pada menguap berdasarkan besarnya tekanan / kempa proses pengarangan. Semakin besar dan suhu dan memperlihatkan tekanan 3 ton (b1) memiliki nilai waktu pengarangan makan semakin banyak zat yang rendah sebesar 7,65\% diikuti dengan tekanan menguap yang terbuang sehingga pada saat 2,5 ton (b2) sebesar 7,77 \% dan tertinggi pada pengujian kadar zat midah menguap akan diperoleh perlakuan tekanan 2 ton (a3) yaitu sebesar $8,00 \%$. kadar zat mudah menguap yang rendah.

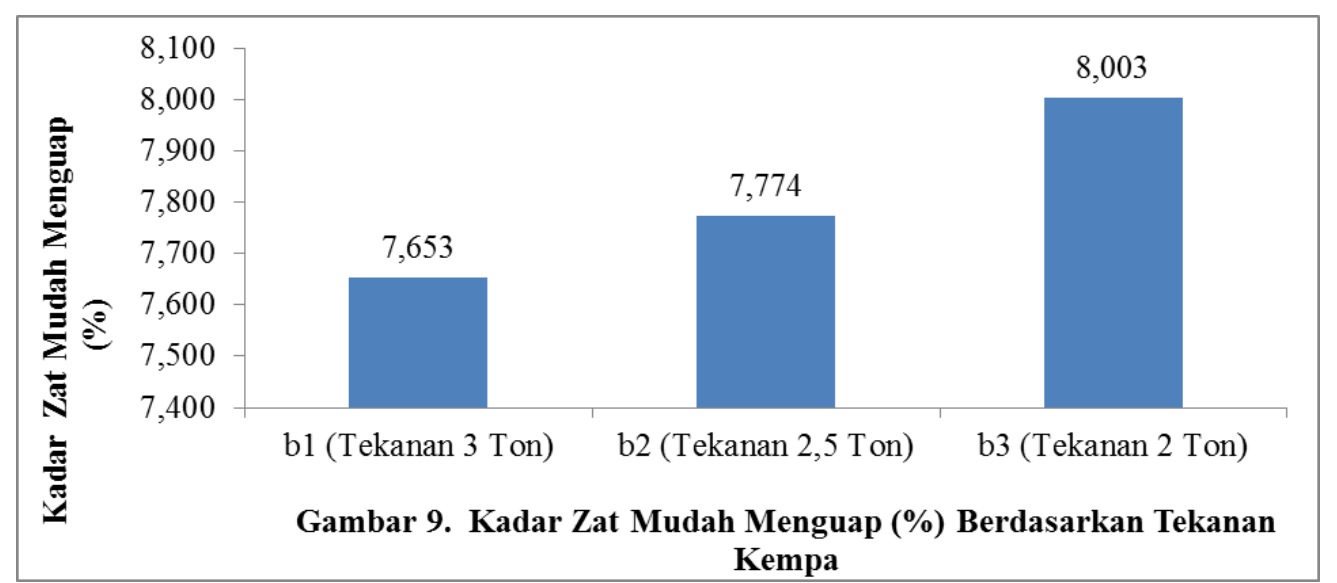

Briket arang pada tekanan 2 ton (b3) diberikan sangat besar, hal ini sesuai dengan memberikan nilai yang cukup tinggi di akibatkan karena kerapatan pada briket arang sangat rendah sehingga mengakibatkan kadar air pada briket arang sangat tinggi dibandingkan dengan tekanan 2,5 ton (b2) dan tekanan 3 ton (b1) kadar zat mudah menguap sangat rendah karena kerapatan sangat tinggi dipengaruhi oleh tekanan yang pernyataan. Berdasarkan hasil analisis sidik ragam terlihat bahwa jenis bambu dan tekanan berpengaruh tidak nyata terhadap perlakuan kadar air kering oven. Jenis bambu (A), tekanan (B) dan interaksinya $(\mathrm{AB})$ berpengaruh tidak nyata terhadap pengaru kadar zat mudah menguap briket arang bambu. Kadar zat mudah menguap yang 
rendah berpeluang menghasilkan nilai kalor yang

Penetapan Kadar Karbon Terikat (Fixed Karbon)

Karbon terikat diindikasikan sebagai fraksi karbon yang terikat didalam arang selain fraksi air, zat menguap dan abu (Rustini, 2004). Keberadaan karbon terikat didalam briket arangdipengaruhi oleh nilai kadar abu dan kadar zat mudah menguap. Kadar kabon terikat akan bernilai lebih tinggi apabila nilai kadar abu dan kadar zat mudah menguap pada briket arang rendah. Kadar tinggi.

karbon terikat berpengaruh terhadap nilai kalor bakar briket arang, Nilai kalor briket arang akan tinggi apa bila nilai kadar karbon terikat pada briket tinggi. Rata - rata kadar karbon terikat briket arang bambu (Bambusa sp) terbesar sebesar 60,456 \% yang diperoleh pada perlakuan bambu jawa dengan tekanan 2 ton (a1b3) dan terendah sebesar 60,295 $\%$. pada perlakuan bambu petung dengan tekanan 2 ton $(\mathrm{a} 2 \mathrm{~b} 3)$.

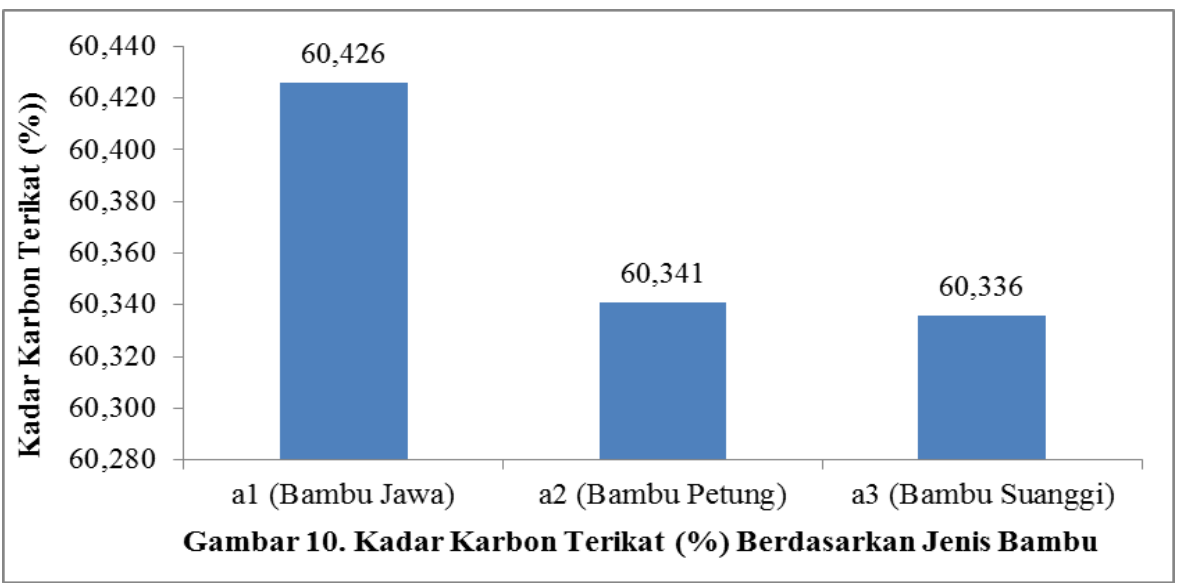

Briket arang bambu jawa (a1) memberikan memperlihatkan tekanan 3 ton (b1) memiliki nilai nilai yang cukup rendah, di bandingkan dengan yang tertinggi sebesar 60,381 \% diikuti dengan bambu suanggi (a3) dan bambu petung (a2) kadar tekanan 2,5 ton (b2) sebesar 60,366\% dan terendah karbon terikat sangat tinggi. Kadar karbon terikat pada perlakuan tekanan 2 ton ( a3) yaitu sebesar berdasarkan besarnya tekanan/kempa $60,350 \%$ dapat dilihat pada Gambar 11. 


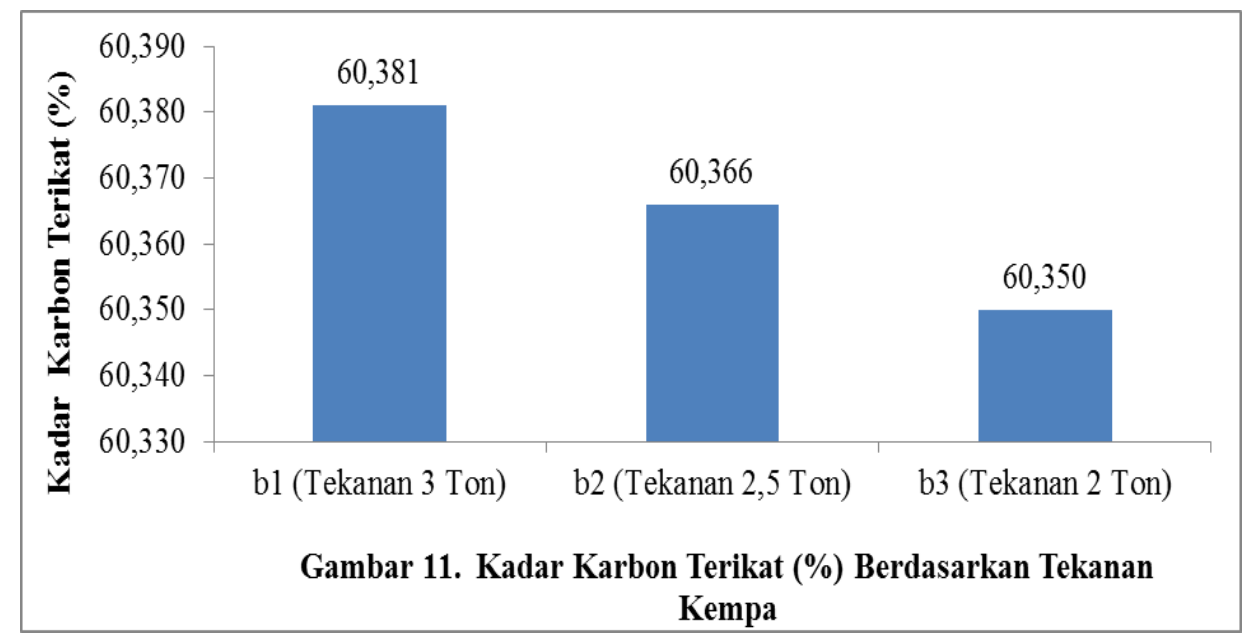

Briket arang dengan tekanan 3 ton (b1) tinggi akan menghasilkan nilai kalor yang tinggi memberikan nilai yang cukup tinggi di akibatkan karena kerapatan pada briket arang sangat tinggi (Sudradjat dan Pari, 2011).

Berdasarkan hasil analisis ragam, terlihat sehingga mengakibatkan kadar karbon terikat pada briket arang sangat tinggi dibandingkan dengan tekanan 2,5 ton (b2) dan tekanan 2 ton (b1) kadar karbon terikat sangat rendah karena kerapatan sangat rendah dipengaruhi oleh tekanan yang diberikan sangat kecil. Kadar karbon terikat yang

\section{Nilai Kalor}

Pengujian terhadap nilai kalor bertujuan untuk mengetahui sejauh mana nilai panas pembakaran yang dihasilkan oleh briket arang. Nilai kalor diperoleh berdasarkan pengukuran pada volume tetap, dimana arang yang dibakar akan menaikan suhu air sehingga nilai kalor arang dapat diukur berdasarkan perbedaan suhu air. Nilai kalor sangat menentukan kualitas arang. Semakin tinggi nilai kalor briket arang semakin baik pula kualitas briket

arang yang dihasilkan. Tinggi rendahnya nilai kalor dipengaruhi oleh jenis bahan baku, kadar air dan kadar abu briket arang, Semakin tinggi kadar air dan kadar abu akan menurunkan nilai kalor briket arang yang dihasilkan, (Rahadian et al., 2013). Rata-rata nilai kalor briket arang bambu (Bambusa sp) terbesar $4833.24 \mathrm{cal} / \mathrm{g}$ yang diperoleh pada perlakuan bambu jawa dengan tekanan 2,5 ton (a1b2) dan terendah sebesar $4336.28 \mathrm{cal} / \mathrm{g}$. pada perlakuan bambu suanggi dengan tekanan 2 ton (a3b3). 


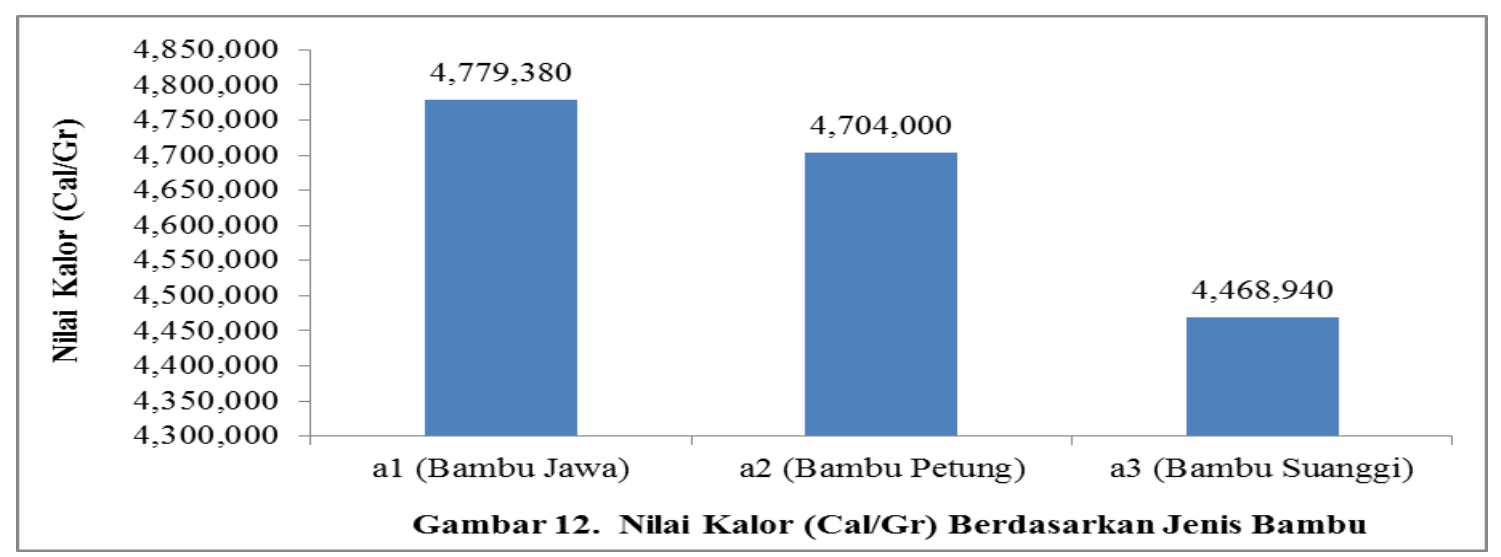

Briket arang bambu jawa (a1) memberikan yang tinggi sebesar $4744.81 \mathrm{cal} / \mathrm{g}$ diikuti dengan nilai kalor yang cukup tinggi di bandingkan dengan tekanan 2,5 ton (b2) sebesar $4604.05 \mathrm{cal} / \mathrm{g}$ dan bambu petung (a2) dan bambu suanggi (a3) rendah pada perlakuan tekanan 2 ton (a3) yaitu memberikan nilai kalor sangat rendah. Nilai kalor berdasarkan besarnya tekanan/kempa sebesar $4603.47 \mathrm{cal} / \mathrm{g}$ dapat dilihat pada Gambar memperlihatkan tekanan 3 ton (b1) memiliki nilai

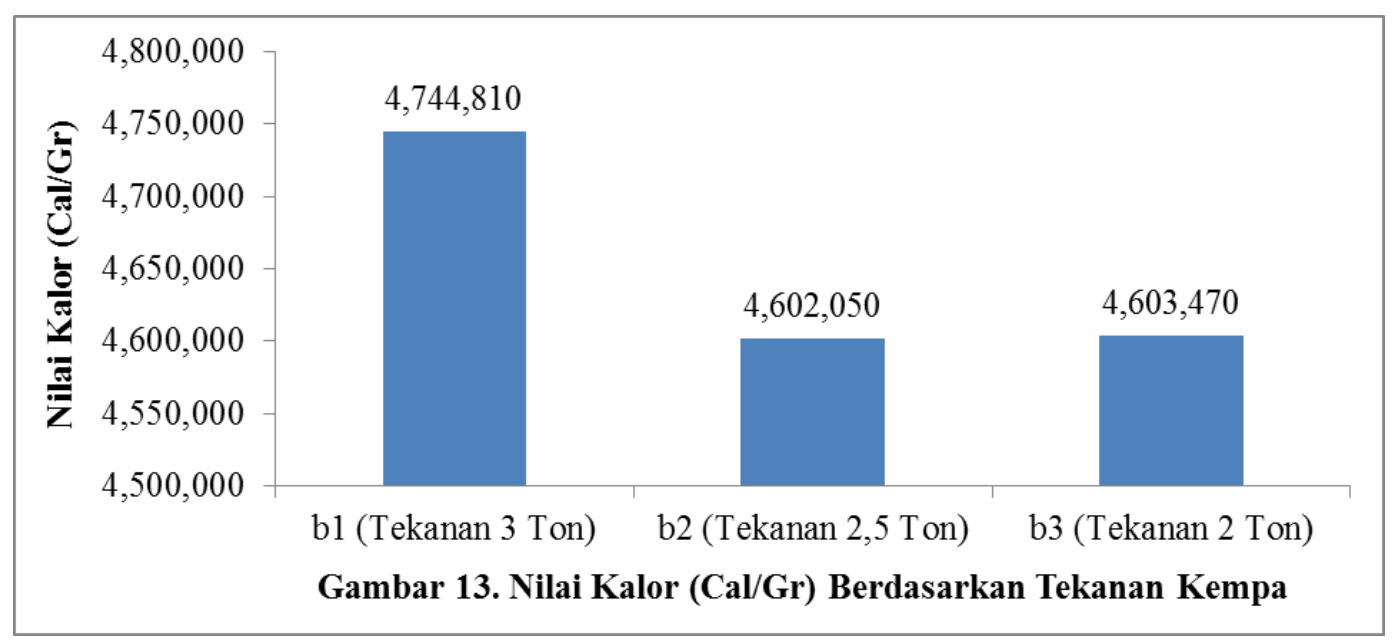

Briket arang dengan tekanan 2 ton (b3) memberikan nilai kalor yang rendah di akibatkan karena kerapatan pada briket arang sangat rendah sehingga mengakibatkan nilai kalor pada briket arang menurun dibandingkan dengan tekanan 2,5 ton (b2) dan tekanan 3 ton (b1) nilai kalor sangat tinggi karena kerapatan sangat tinggi dipengaruhi oleh tekanan yang diberikan sangat besar. Berdasarkan hasil analisis sidik ragam, terlihat bahwa jenis bambu dan tekanan berpengaruh sangat nyata dan tidak nyata terhadap perlakuan nilai kalor. Hasil rata-rata pengaruh jenis bambu terhadap nilai kalor dalam bentuk persen dimana perlakuan bambu jawa (a1) mempunyai nilai kalor yang tinggi bila di bandingkan dengan perlakuan bambu petung (a2) dan bambu suanggi (a3) memiliki nilai kalor yang rendah. Jenis bambu (A), berpengaru sangat nyata terhadap nilai kalor, sedangkan tekanan (B) dan interaksinya (AB), berpengaruh tidak nyata terhadap nilai kalor briket 
arang bambu. Nilai kalor sangat menentukan kualitas briket arang (Budi, 2017). Nilai kalor yang

\section{KESIMPULAN}

Parameter untuk menentukan kualitas briket arang dipengaruhi oleh beberapa faktor yaitu: kadar air kering udara (kaku) arang briket bambu, berkisar antara 6,54\%-6,62\%, kadar Air Kering Oven (kako) Arang Briket Bambu, berkisar antara 3,412\%- 3,461, kadar abu arang briket bambu berkisar antara 3,127\% - 5,227\%, kadar zat mudah

\section{DAFTAR PUSTAKA}

Anggoro, D.D., Uhammad D.H.W dan M.Z. Fathoni. 2017. Pembuatan briket arang dari campuran tempurung kelapa dan serbuk gergaji kayu sengon. Ejurnal Teknik 38: 76-80.

Badan Penelitian dan Pengembangan Kehutanan, 2014. Pedoman Teknis Pembuatan Briket Arang. Departemen Kehutanan Bogor.

Esman, B. 2017. Pemanfaatan briket arang tempurung kelapa sebagai sumber energi alternatif. Jurnal Sarwahita 14.

Faulina, A., S. Andari, D. Anggraeni. 2011. Response Surface Methodology (RSM) dan Aplkasinya, Surabaya. Institut Sepuluh Nopember.

Hastiawan, I., Haryono, E. Ernawati, A.R. Novianti, D.R. Eddy, Rukiah, dan B. Yuliati. 2016. Pembuatan Briket Dari Limbah Bambu Dengan Memakai Adhesive Pet Plastil Di Desa Cilayung, Jatinangor.

Hendra. D. 2007. Pembuatan briket arang dari campuran kayu, bambu, sabut kelapa dan tempurung kelapa sebagai energi alternatif. Jurnal Penelitiann Hasil Hutan 25: 242-255. tinggi diperlukan untuk proses pembakaran karena menghasilkan panas yang tinggi pula.

menguap arang briket bambu berkisar antara 6,64\% - 9,67\%, kadar karbon terikat arang briket bambu berkisar antara 59,294\% - 61,401\%, nilai kalor arang briket bambu berkisar antara 4833.24 4336.28 Cal/g. Jenis bambu (A) berpengaruh terhadap kadar air kering udara dan nilai kalor, sedangkan faktor tekanan kempa (B) dan interaksi (AB) berpengaruh terhadap kadar air kering udara.

Gaspersz, V. 1989. Metode Perancangan Untuk Ilmu-Ilmu Pertanian dan Ilmu-Ilmu Teknik dan Biologi. Penerbit ARMICO.

Gusmailina, 2010. Pengaruh Arang Kompos Bioaktif Terhadap Pertumbuhan Anakan Bulian. Jurnal Penelitian Hasil Hasil Hutan, 28(2), 1-26.

Hendra D, Darmawan S, 2000. Pembuatan Briket Arang Dari Serbuk Gergajian Kayu dengan Penambahan Tempurung Kelapa. Buletin Penelian Hasil Hutan Vol 18 No 1 (2000) pp 1-9. Bogor.

Hendra D, Pari G, 2000. Penyempurnaan Teknologi Pengolahan Arang. Laporan Hasil Penelitian Pusat Penelitian Hasil Hutan. Badan Peneliti dan Pengembangan Kehutanan, Bogor.

Rustini, 2004. Pembuatan Briket Arang Dari Serbuk Gergaji Kayu Pinus (Pinus merkusii) Dengan Penambahan Tempurung Kelapa (Skripsi) Bogor. Jurusan Teknologi Hasil Hutan, Fakultas Kehutanan, Institut Pertanian Bogor.

Sarjono (2013). Studi Eksperimen Perbandingan Nilai kalor Briket Capuran Bioarang Sekam Padi dan Tempurung Kelapa. Majalah Ilmiah STTR Cepu, 11(17) 11-19. 
Sudradjat R dan Gustam Pari, 2011. Arang Aktir, Teknologi Pengolahan dan Masa Depannya. Badan Penelitian dan Pengembangan-Kementerian Kehutanan. ISBN : 978-979-3132-38-9.

Standar Nasional Indonesia. 2000. SNI Briket Arang Kayu SNI 01-6235-2000. Badan Standarisasi Nasional-BSN.

Putro, S, Musabbaikhah dan Sri Hartati, 2014. Setting Parameter Yang Optimal Pada Proses Pembriketan Limbah Biomasa Guna Mendapatkan Kadar Air Briket Minimal
Dalam Menciptakan Energi Alternatif Yang Ekonomis, Universitas Muhammadiyah Surakarta.

Rahadian D., Aji Muhammad,. Nur Her Riyadi Parnanto, Fanny Widadie, 2013. Kajian Peningkatan Mutu Briket Arang Tempurung Kelapa Dengan Alat Pengering Tipe Rak Berbahan Bakar Biomasa. Jurnal Teknologi Hasil Pertanian, Vol VI No 1, Februari 2013.

Wibowo, W.W. 2012. Menghitung Nilai Kalor. Penerbit Kanisius - Yogyakarta. 